\title{
Entrepreneurial Land Developers: Joint Production, Local Externalities, and Mixed Housing Developments*
}

\author{
Hideo Konishi ${ }^{\dagger}$
}

\begin{abstract}
Housing developments (condos and suburban developments) are not necessarily homogeneous. Developers provide different types of units of various sizes and other characteristics catering to different types of customers. In this paper, we allow joint production and local consumption externalities within each development, and show that land developers who seek a profit-maximizing set of units in developments may provide mixed developments. We show that there exists an equilibrium, and that every equilibrium is Pareto efficient. We provide examples in which mixed developments arise in a long-run equilibrium. We relate this work to a widely used hedonic pricing model by Rosen (1974), and to an equilibrium concept under asymmetric information by Rothschild and Stiglitz (1976).
\end{abstract}

Keywords: land developers, mixed development, joint production, consumption externalities, efficiency, equilibrium, entrepreneurship, hedonic pricing

${ }^{*}$ I thank Yves Balasko, Marcus Berliant, John Conley, Tom Davidoff, Hans Haller, John Weymark, Myrna Wooders, and in particular Tom Holmes for their comments. I also thank two anonymous referees and the Editor Bob Helsley for providing a number of comments that improved the readability of the paper tremendously. I thank Chen-Yu Pan for his research assistance. This paper has been presented at the RSAI in San Francisco 2009, the APET/PGPPE in Istanbul 2010, the Econometric Society World Congress in Shanghai 2010, and at seminars in Kyoto, Vanderbilt, and Virginia Tech.

${ }^{\dagger}$ Department of Economics, Boston College, USA. (E-mail) hideo.konishi@bc.edu 


\section{Introduction}

In the real world, we observe both developments with identical housing or condo units and developments with multiple types of units (mixed developments). Condos in the same complex are typically composed of units of different sizes. Similarly, in some new suburban developments, we also observe houses of different sizes in the same development. Why do land developers build heterogeneous developments? According to Tiebout (1956), consumers sort by their preferences into their most preferred developments, and as a result efficient allocations with homogeneous developments should be realized. If so, does this mean that mixed developments are inefficient? Aren't these land developers maximizing their profits?

To answer these questions, we will consider two realistic situations. First, the housing in a development is produced by a joint production technology. For example, a penthouse with a nice view can be produced only with other units in a multistory condo building, and a house prestigiously located on a human-made pond in a suburban development necessarily comes with other houses in less-prestigious locations. Second, there are neighborhood externalities in housing consumption - a resident's utility is affected not only by the characteristics of her own house, but also by those of her neighbors' houses. In this paper, we will provide some answers to the above questions when joint production of housing and/or consumption externalities are present.

Consider a land developer who plans to build multiple houses in a development using joint production technology. Of course, a consumer cares about her housing unit's basic characteristics such as its size, but she may also care about its associated prestige in the development. If consumers who care about prestige tend to prefer more luxurious units, then the land developer should take this information into account. For example, in building a high-rise condo, she might build large and luxurious units on the upper floors to attract wealthy consumers who care about nice views and luxurious interiors, while building smaller and modest units on the lower floors to serve households with more average tastes. Similarly, in a suburban development, a developer might build a higher-standard house in the central location, hoping that it will be purchased by a wealthy customer who is willing to pay a higher price for that location. That is, as long as there are consumers who prefer these prestigious units and are willing to spend more money for luxurious units, a developer should choose the level of luxury for each unit depending on its level of prestige in the development. 
In some cases, such concern with prestige may be motivated by consumer psychology - consumption externalities from their neighbors' houses. Although the result may be observationally very similar to the previous example, it is easy to explain how providing mixed developments may be more profitable than providing homogeneous developments given such consumption externalities. Consider the following example. Each development is composed of two houses, and there are two types of consumers: type 1 does not care about her neighbor's house, while type 2 prefers having a more luxurious house than her neighbor. In this case, if a type 2 consumer is coupled with another type 2 , then it is not optimal for the land developer to provide two equally luxurious, houses since the residents discount their utilities by their houses not being the dominating ones. Instead, if type 1 and type 2 are combined in the same development, the developer can offer a very luxurious house to type 2 without making the other (type 1) resident jealous. Thus, providing a mixed development may optimize the composition of houses, resulting in higher profits to developers. ${ }^{1}$

The main objective of this paper is to model an economy with various housing developments under a natural equilibrium definition by allowing entrepreneurial land developers to freely provide any kind of developments. We allow for joint production and consumption externalities. With an appropriate equilibrium concept involving entrepreneurial developers, we will show that (i) there exists an equilibrium, (ii) equilibrium allocations may involve mixed developments, and (iii) equilibrium allocations are all Pareto efficient. That is, although Tiebout's efficiency claim is still justified by consumers' voting with their feet, his homogeneity (segregation) claim does not necessarily hold given joint production and/or consumption externalities.

Introducing entrepreneurial developers into a general equilibrium model with a housing/land market is not new. Henderson (1974) considers a model in which a system of a finite number of cities evolves endogenously when intracity Marshallian externalities in production are present. Although his main analysis takes an evolutionary approach, he discusses the role of entrepreneurship. If entrepreneurs can form new communities whenever it is

\footnotetext{
${ }^{1}$ In the main analysis, we allow for more general consumption externalities than negative externalities from neighboring houses. For our main results (the existence of equilibrium and the first welfare theorem), we do not need to restrict types of externalities to negative externalities: positive externalities (nicely maintained neighboring houses make the residents happy) and more complicated externalities (preference for relative size of neighbors' houses and the consumer's own house) are all allowed.
} 
profitable to do so, then the resulting competitive equilibrium allocation is Pareto efficient, if it exists. Helsley and Strange (1997) consider the case where (city) developers who provide local public goods have limited power by introducing a geographical structure into their model explicitly (thus entry is limited), and show that subgame perfect equilibrium can generate an inefficient allocation even if consumers are homogeneous - some lots may not be developed and local public goods may be underprovided.

In contrast, we consider an economy with a large number of atomless land developers who can enter the market freely in an idealized version of Tiebout's (1956) world along the lines of Ellickson et al. (1999) and Allouch et al. (2009). There is a continuum of atomless consumers of multiple preference/endowment types, while each development has only finitely many housing units. Thus, there will be a continuum of atomless developments, a feature that allows us to have an idealized competitive market (Aumann 1964). Land developers decide the characteristics of housing units in the developments by targeting a type of consumer for each unit they sell. They know the distribution of consumers' preference types, although they cannot (price-)discriminate between consumers by preference type. They can provide local amenities (for example, landscaping and common swimming pools) and can build houses with different characteristics. The feasibility of a profile of housing units in a development is restricted by joint production technology (joint production). In addition, a consumer's house consumption may affect his or her neighbors' utilities (consumption externalities). While the consumers can choose their houses from the existing developments, the land developers can creatively provide new types of development with varying compositions of types of housing units, if profit opportunities remain in the market (entrepreneurship). We prove the existence of equilibrium, and show that every refined equilibrium is Pareto efficient despite the presence of consumption externalities.

Our paper differs from Ellickson et al. (1999) and Allouch et al. (2009) conceptually and technically, although these papers prove the existence and efficiency of equilibria in related economies. First, our equilibrium concept does not assume a complete price system. Under economic agents' pricetaking behavior, the assumption that markets exist only for the existing types of houses implies that there will be economic inefficiency because of the lack of variety of house types (for example, if all housing units are of the same type, then consumers have no choice). To fix this problem, we employ entrepreneurial land developers's profit-motives following Henderson 
(1974) and Helsley and Strange (1997). Assuming that land developers are profit-seeking entrepreneurs, they will contemplate whether providing a new type of development is more profitable than existing development types. In equilibrium there are no profit opportunities left for entrepreneurial land developers, although consumers choose from the existing house stock. Second, although Ellickson et al. (1999) and Allouch et al. (2009) introduce externalities within a club, they assume that externalities are caused by "observable" types and that club managers can charge type-dependent membership fees. ${ }^{2}$ In contrast, in our paper, we assume the existence of consumption externalities (from housing), and that land developers are not allowed to discriminate between consumers by their types. Third, the presence of (local) consumption externalities requires a stronger assumption to guarantee the existence of equilibrium. We need convex preferences (including other consumers' housing consumption), although we are dealing with an atomless economy. This is because our proof needs to ensure that there is an intradevelopment Paretoefficient allocation for each economic condition, such as the market price vector and the outside opportunity for each type of consumer.

This paper can also be regarded as an extension of Rosen's (1974) hedonic price model. In his model, Rosen considers (implicit) prices for all possible characteristics of a house and applies standard market equilibrium analysis. He shows that the hedonic price equilibrium is Pareto efficient. Although with consumption externalities hedonic price equilibrium may not exist (even if a house has the same characteristics as another, the price of the house depends on the neighbors' housing characteristics), we can establish a formal connection between our equilibrium concept and an extended hedonic price equilibrium. ${ }^{3}$ A house's profile is now a list of the characteristics of the unit and those of the other housing units in the same development. The hedonic price function for such an extended definition of housing characteristics constitutes a complete price system for all possible (extended) housing characteristics and supports a Pareto-optimal allocation. Developers and consumers are price-takers, and a nonexisting house type in equilibrium is just the result of nobody wanting to buy that type of house and no developer wanting to supply that type of house under the prevailing hedonic price. Although our entrepreneurial equilibrium does not use a complete price system,

\footnotetext{
${ }^{2}$ Luque (2010) considers an interesting model with heterogeneous labor-types and laborcomplementarity in production. He proves the existence and efficiency of equilibrium with anonymous pricing by utilizing labor-type dependent wages.

${ }^{3}$ I thank Tom Holmes for his insightful comments on this issue.
} 
entrepreneurial equilibrium and extended hedonic price equilibrium turn out to be equivalent.

The rest of the paper is organized as follows. Section 2 describes how developers' profit-maximizing behavior achieves intrajurisdictional Pareto efficiency with a simpler model, and provides two examples to illustrate how joint production and consumption externalities affect equilibrium allocations and prices. Section 3 describes our housing market model with consumption externalities and introduces an equilibrium concept with entrepreneurial land developers. Section 4 proves the existence and efficiency of entrepreneurial equilibrium under optimism by developers and consumers. In section 5 , we show the equivalence between extended hedonic price equilibrium and entrepreneurial equilibrium. Section 6 concludes.

\section{Quasi-Linear Model and Examples}

In this section, we discuss a simplified model in which consumers have quasilinear utilities and deep pockets (no endowment constraint), and explain how the profit maximization by land developers leads to the first-best outcome. We also give examples that illustrate how consumption externalities affect equilibrium housing prices. Each consumer is endowed with a numeraire good, and developers build housing developments by using a numeraire good. Let each house $h$ be characterized by its size $z_{h} \in \mathbb{R}_{+}$, and let $C(z, H)=\sum_{h=1}^{H} z_{h}+F(H)$, where $z=\left(z_{1}, \ldots, z_{H}\right)$ and $F(H) \geq 0$, be the cost of construction of all housing in a development. We interpret $F(H)$ as a fixed cost to produce $H$ houses in a development, and the marginal cost of enlarging a house size is unity. There are many potential land developers who can enter the market freely.

There are multiple types of consumers with different quasi-linear utility functions: if type $\theta$ consumer occupies unit $h$ when a development is composed of houses with sizes $\left(z_{1}, z_{2}, \ldots, z_{H}\right)$ then

$$
u^{\theta}\left(-p_{h}, z, h\right)=-p_{h}+v^{\theta}\left(z_{h}\right)+\sum_{\tilde{h} \neq h} g^{\theta}\left(z_{\tilde{h}}\right),
$$

where $v^{\theta}\left(z_{h}\right)$ is the utility from her own house, $g^{\theta}\left(z_{\tilde{h}}\right)$ is the externality from a neighbor's house $\tilde{h}$, and $p_{h}$ is the price of house $h$ measured by the numeraire good. If the sign of $g^{\theta}\left(z_{\tilde{h}}\right)$ is negative (positive), then type $\theta$ consumer gets negative (positive) externalities from neighbors' houses. We assume 
that all types of consumers have sufficiently large amount of numeraire good endowments so that any consumer can purchase any house (the numeraire good endowment is normalized to zero). We assume that $v^{\theta}$ and $g^{\theta}$ are

concave functions with $v^{\theta}(0)=g^{\theta}(0)=0$, and $v^{\theta}$ is monotonically increasing. Consumers choose their favorite house in the most suitable development. There is a continuum of atomless consumers for each type, and the population measure of type $\theta$ consumers is denoted by $N^{\theta}$. Since $H$ is finite, there will be a continuum of developments in each allocation.

\subsection{Market Equilibrium and Pareto Efficiency}

Here, we show that profit-maximizing developer chooses an intra-development Pareto efficiency even in the presence of consumption externalities. First, we characterize the market equilibrium allocation. Assuming the size of the development is $H$, a profit-maximizing land developer's optimization problem is described as:

$$
\max _{\left(p_{h}, z_{h}\right)_{h \in H}} \sum_{h \in H} p_{h}-C(z)
$$

under the following $H$ constraints: for all $h=1, \ldots, H$, there exists $\theta_{h} \in \Theta$ such that

$$
u^{\theta_{h}}\left(-p_{h}, z, H, h\right)=U^{\theta_{h}},
$$

where $U^{\theta_{h}}$ is type $\theta_{h}$ 's utility that can be achieved in the market (consumers are freely mobile). Assuming that the target type $\theta_{h}$ for each unit $h=1, \ldots, H$ is known, the land developer chooses $p=\left(p_{1}, \ldots, p_{H}\right)$ and $z=\left(z_{1}, \ldots, z_{H}\right)$ in order to maximize her profit. She can set up a Lagrangian:

$$
L=\sum_{h \in H} p_{h}-C(z)+\sum \lambda_{h}\left[u^{\theta_{h}}\left(-p_{h}, z, H, h\right)-U^{\theta_{h}}\right] .
$$

Since $u^{\theta}$ is concave in $x$ and $z$, this problem is a convex-planning problem. Using (1), the first-order conditions for (4) are:

$$
\begin{gathered}
\lambda_{h}=1 \text { for all } h=1, \ldots, H \\
1=v^{\theta_{h^{\prime}}}\left(z_{h}\right)+\sum_{\tilde{h} \neq h} g^{\theta_{h^{\prime}}}\left(z_{\tilde{h}}\right) \text { for all } h=1, \ldots, H
\end{gathered}
$$

In the long-run equilibrium, land developers earn zero profit, so we have

$$
\sum_{h \in H} p_{h}-C(z)=0
$$


Now, consider an intradevelopment Pareto-efficient allocation. The intradevelopment feasibility requirement is

$$
\sum_{h \in H} p_{h}-C(z)=0
$$

Thus, the Lagrangian is

$$
\mathcal{L}=\sum \mu_{h}\left[u^{\theta_{h}}\left(-p_{h}, z, H, h\right)-U^{\theta_{h}}\right]+\nu\left[\sum_{h \in H} p_{h}-C(z)\right]
$$

Then, using (1), the first-order conditions for (9) are simply written as:

$$
\begin{gathered}
\frac{\mu_{h}}{\nu}=1 \text { for all } h=1, \ldots, H \\
1=v^{\theta_{h^{\prime}}}\left(z_{h}\right)+\sum_{\tilde{h} \neq h} g^{\theta_{h^{\prime}}}\left(z_{\tilde{h}}\right) \text { for all } h=1, \ldots, H
\end{gathered}
$$

Since the profit-maximization conditions (6) and (7) are equivalent to the Pareto-efficiency conditions (11) and (8), we can see that land developers' profit-maximizing behavior internalizes consumption externalities within developments to achieve efficiency of the development. Still, it is not clear from the above analysis how entrepreneurial land developers interact with each other in the market given the population distribution of consumer types. In the following two subsections, we explicitly calculate market equilibria in two simple examples.

\subsection{Joint Production: Two-Story Condo Buildings}

Let us start with the "no local consumer externality" case. Suppose there are two types of consumers $\theta=1,2$ with the same population $N^{1}=N^{2}$ (typically, modest and wealthy households, respectively). Land developers can build two-story buildings in which each floor has one condo unit. Land developers can make each unit either luxurious or modest $z=L, M$, where $L$ and $M$ denote unit's "quality" instead of "size" — luxurious and modest, respectively. That is, the land developer's choice is $\left(z_{1}, z_{2}\right)=(L, L),(L, M)$, $(M, L)$, and $(M, M)$, where $z_{1}$ and $z_{2}$ indicate the first- and second-floor units' qualities, respectively. Each consumer cares not only about which floor she lives on, but also about how many floors the condo building has. Suppose 
that $u^{\theta}\left(-p, h, z_{h}\right)=-p+v^{\theta}\left(h, z_{h}\right)$. As an example, the cost of buiding a two-story condo with modest interiors is 12 , and the cost of upgrading each unit to a luxurious unit is 5 . The values of the two types of consumers' utility functions are summarized in the following table:

\begin{tabular}{|l|c|c|c|c|}
\hline & $v^{\theta}(1, M)$ & $v^{\theta}(1, L)$ & $v^{\theta}(2, M)$ & $v^{\theta}(2, L)$ \\
\hline$\theta=1$ & 5 & 7 & 7 & 9 \\
\hline$\theta=2$ & 4 & 10 & 8 & 16 \\
\hline
\end{tabular}

Suppose that there are only $(M, M)$ condos. If two type 1 consumers are living in such a condo, the one on the first floor pays 5 and the one on the second floor pays 7 . In total, the building cost 12 is just recovered. Similarly, if two type 2 consumers are living in a condo $(M, M)$, then the ones on the first and second floors pay 4 and 8, respectively, and again the building cost 12 is just recovered. However, this is clearly not an equilibrium allocation. In a condo that is occupied by type 1 consumers, the second floor unit costs only 7 , and a type 2 consumer would move in since her benefit from the second floor unit is 8. Similarly, a type 1 consumer would move into the first floor unit, occupied by type 2 only. Since we assumed $N^{1}=N^{2}$, all condo buildings' first floors will be occupied by type 1 and the second floors will be occupied by type 2 consumers in equilibrium when there are only $(M, M)$ condos, and the (zero-profit) equilibrium prices of the first- and second-floor units, $p_{1}^{(M, M)}$ and $p_{2}^{(M, M)}$, satisfy (i) $p_{1}^{(M, M)}+p_{2}^{(M, M)}=12$, (ii) $p_{1}^{(M, M)} \leq 5$, and (iii) $p_{2}^{(M, M)} \leq 8 .^{4}$

However, this is not a long-run equilibrium, since land developers can upgrade the second floor units occupied by type 2 consumers. In the previous equilibrium allocation, type 2 consumers are getting utility $u_{2}=8-p_{2}^{(M, M)}$, so land developers can charge $p_{2}^{(M, L)}=16-u_{2}=16-8+p_{2}^{(M, M)}=8+p_{2}^{(M, M)}$ by spending upgrading cost 5 , since $p_{2}^{(M, L)}-5=8+p_{2}^{(M, M)}-5>p_{2}^{(M, M)}$. This is clearly profit-improving. However, in the long run, all profit opportunities disappear by free entry of land developers. Thus, in the long-run equilibrium, there are only $(M, L)$ type condos in which the first and second floors are occupied by types 1 and 2 consumers, and equilibrium prices $p_{1}^{(M, L)}$ and $p_{2}^{(M, L)}$ satisfy (i) $p_{1}^{(M, L)}+p_{2}^{(M, L)}=17$, (ii) $p_{1}^{(M, L)} \leq 5$, and (iii) $p_{2}^{(M, L)} \leq 16$.

\footnotetext{
${ }^{4}$ The indeterminacy of market equilibrium prices comes from our simplification assumption $N^{1}=N^{2}$. If the populations of these two types are different, equilibrium prices would be pinned down, as will be seen in the next subsection.
} 


\subsection{Two Types of Consumers with Local Externalities}

This is a formal version of the example that we described in the introduction (a negative externality case). Suppose that $H=2$ in all developments (so only two housing units developments are allowed) and that there are two types of consumer. Moreover, the fixed cost of establishing a development is zero: i.e., $C\left(z_{1}, z_{2}\right)=z_{1}+z_{2}$. A type 1 consumer who occupies a house with size $z$ does not care about the other's house size $\hat{z}: g^{1}(\hat{z})=0$; a type 2 consumer who occupies a house of size $z$ gets disutility from the other resident's having a large house size $\hat{z}: g^{2 \prime}(\hat{z})<0$. Define $z^{1 *}$ and $z^{2 *}$ by $v^{1 \prime}\left(z^{1 *}\right)=1$ and $v^{2 \prime}\left(z^{2 *}\right)=1$ : that is, $z^{1 *}$ and $z^{2 *}$ are the optimal sizes of houses for types 1 and 2, respectively, by ignoring externalities.

Consider a development with only type 1 consumers as residents (development type $\{1,1\})$. In this case, there is no externality, and a land developer should offer size $z^{\{1,1\}}=z^{1 *}$ houses in order to maximize the profit. The price of the house should be $p^{\{1,1\}}=v^{1}\left(z^{1 *}\right)-U^{1 *}$, given that the market prevailing utility is $U^{1 *}$ which is to be determined in the market equilibrium.

Second, consider a development with only type 2 consumers. Then the optimal size house (with externalities) for development type $\{2,2\}$ is characterized by

$$
1=v^{2 \prime}\left(z^{\{2,2\}}\right)+g^{2 \prime}\left(z^{\{2,2\}}\right) .
$$

This implies that the optimal size in a type 2 development satisfies $z^{\{2,2\}}<$ $z^{2 *}$. The price of housing should be set to $p^{\{2,2\}}=v^{2}\left(z^{\{2,2\}}\right)-v^{2}\left(z^{\{2,2\}}\right)-U^{2 *}$. Let us assume $z^{1 *}<z^{\{2,2\}}$.

Now, consider the case of a mixed development (development type $\{1,2\}$ ). For convenience, type 1 is assigned to the first house, and type 2 is assigned to the second: that is, $z_{1}^{\{1,2\}}$ is the size of the house type 1 has, and $z_{2}^{\{1,2\}}$ is the size of the house type 2 has. Type 1 consumers do not get externalities from type 2's house size, while type 2 gets negative satisfaction from type 1 consumers' house size. This means that if $z^{1 *}<z_{2}^{\{2,2\}}$, then by coupling these two consumers, the land developer can make a higher profit: even if he offers sizes $z_{1}^{\{1,2\}}=z^{1 *}$ and $z_{2}^{\{1,2\}}=z^{\{2,2\}}$ houses to consumers of types 1 and 2 , respectively, this developer can charge a higher price to the type 2 consumer by $\left|g^{2}\left(z^{\{2,2\}}\right)\right|-\left|g^{2}\left(z^{1 *}\right)\right|$ since this consumer is happier with a smaller neighbor's house. Actually, the developer can do better than that. Since type 1

\footnotetext{
${ }^{5}$ This is assumed for expositionary convenience. As is easily checked, even if this condition is violated, a mixed development can dominate homogeneous developments.
} 
does not care how large type 2's house is, the developer can enlarge type 2's house to $z_{2}^{\{1,2\}}=z^{2 *}$ from $z^{\{2,2\}}$ without affecting type 1's utility, adding surplus equal to the shaded area in Figure 1. Now, at $z_{1}^{\{1,2\}}=z^{1 *}, v^{1 \prime}\left(z^{1 *}\right)=1$ holds, but negative externality to type $2, g^{2 \prime}\left(z^{1 *}\right)<0$, is not accounted. By reducing $z_{1}^{\{1,2\}}$ to lower than $z^{1 *}$ to satisfy $v^{1 \prime}\left(z_{1}^{\{1,2\}}\right)+g^{2 \prime}\left(z_{1}^{\{1,2\}}\right)=1$, the developer can achieve the highest profit, avoiding deadweight loss of the shaded area in Figure 2.

\section{[Figures 1 and 2 here]}

Then what will the long-run equilibrium prices be? It depends on the population ratio of types 1 and 2 . If type 1 is more numerous than type 2 in the population, then the developers cannot have only mixed developments. So, there will be developments with only type 1 . Since developers cannot make a profit in the long run, the market price of houses for type 1 must be $p^{\{1,1\}}=z^{1 *}$ in the homogeneous development. This gives type 1 utility $U^{1 *}=v^{1}\left(z^{1 *}\right)-z^{1 *}$. This pins down the price of the type 1 consumer's house in mixed developments: $p_{1}^{\{1,2\}}=v^{1}\left(z_{1}^{\{1,2\}}\right)-v^{1}\left(z^{1 *}\right)+z^{1 *}$. Thus, the type 2 consumer consumes $z_{2}^{\{1,2\}}=z^{2 *}$ paying $p_{2}^{\{1,2\}}=z_{1}^{\{1,2\}}+z^{2 *}-p_{1}^{\{1,2\}}$, since in the long run, the developers cannot earn a profit. As a result, because of their scarcity, type 2 consumers enjoy higher utilities $U^{2 *}=v^{2}\left(z^{2 *}\right)+$ $g^{2}\left(z_{1}^{\{1,2\}}\right)-p_{2}^{\{1,2\}}$. On the other hand, if type 1 is relatively scarce, there will be developments populated by only type 2 , so $U^{2 *}=v^{2}\left(z^{\{2,2\}}\right)+g^{2}\left(z^{\{2,2\}}\right)-z^{\{2,2\}}$ since the zero-profit condition implies $p^{\{2,2\}}=z^{\{2,2\}}$. This pins down $p_{2}^{\{1,2\}}$ and then $p_{1}^{\{1,2\}}$. In this case, type 1 enjoys scarcity of its type. The following numerical example illustrates these claims:

Numerical Example. Let $v^{1}(z)=3.5 \log (1+z), v^{2}(z)=5 \log (1+z)$, and $g^{2}(\hat{z})=-\frac{(\hat{z})^{2}}{12}$. Then, the f.o.c.s are

$$
\begin{aligned}
v^{1 \prime}\left(z^{1 *}\right) & =\frac{3.5}{1+z^{1 *}}=1, \\
v^{2 \prime}\left(z^{2 *}\right) & =\frac{5}{1+z^{2 *}}=1, \\
v^{2 \prime}\left(z^{\{2,2\}}\right)+g^{2 \prime}\left(z^{\{2,2\}}\right) & =\frac{5}{1+z^{\{2,2\}}}-\frac{z^{\{2,2\}}}{6}=1,
\end{aligned}
$$




$$
v^{1 \prime}\left(z_{1}^{\{1,2\}}\right)+g^{2 \prime}\left(z_{2}^{\{1,2\}}\right)=\frac{3.5}{1+z_{1}^{\{1,2\}}}-\frac{z_{2}^{\{1,2\}}}{6}=1 .
$$

Thus, we obtain $z^{1 *}=z^{\{1,1\}}=2.5, z^{2 *}=z_{2}^{\{1,2\}}=4, z^{\{2,2\}}=2.5208$, and $z_{1}^{\{1,2\}}=1.7202$. These values generate the following values:

$$
\begin{gathered}
v^{1}\left(z^{\{1,1\}}\right)=3.5 \log (1+2.5)=4.3847 \\
v^{1}\left(z_{1}^{\{1,2\}}\right)=3.5 \log (1+1.7202)=3.5025 \\
v^{2}\left(z_{2}^{\{1,2\}}\right)-g^{2}\left(z_{1}^{\{1,2\}}\right)=5 \log (1+4)-\frac{(1.7202)^{2}}{12}=7.8006 \\
v^{2}\left(z^{\{2,2\}}\right)-g^{2}\left(z^{\{2,2\}}\right)=5 \log (1+2.5208)-\frac{(2.5208)^{2}}{12}=5.7639 .
\end{gathered}
$$

The long-run equilibrium allocation can be described using the following table:

\begin{tabular}{|c|c|c|c|c|}
\hline & $\{1,1\}$ & $\{2,2\}$ & $\{1,2\}: N^{1}>N^{2}$ & $\{1,2\}: N^{1}<N^{2}$ \\
\hline$U^{1 *}$ & 1.8847 & & 1.8847 & 3.3519 \\
\hline$U^{2 *}$ & & 2.2310 & 3.6982 & 2.2310 \\
\hline$z^{1}$ & 2.5000 & & 1.7202 & 1.7202 \\
\hline$z^{2}$ & & 2.5208 & 4.0000 & 4.0000 \\
\hline$p_{1}$ & 2.5000 & & 1.6178 & 0.1506 \\
\hline$p_{2}$ & & 2.5208 & 4.1024 & 5.5696 \\
\hline
\end{tabular}

We can make the following observations.

- In both homogeneous developments $\{1,1\}$ and $\{2,2\}$, the sizes of houses are almost the same, $z^{1 *}=2.5$ and $z^{2 *}=2.5208$. That is, as long as only homogeneous developments are provided, there is almost no variety for consumers. ${ }^{6}$

- Once mixed developments are allowed, the mixed-development houses are $\left(z_{1}^{\{1,2\}}, z_{2}^{\{1,2\}}\right)=(1.7202,4)$, which are quite heterogeneous in sizes.

- There is no equilibrium with only homogeneous developments, since mixed developments achieve a higher total surplus.

\footnotetext{
${ }^{6}$ It is easy to adjust the parameters to make $z_{\{1,1\}}^{1}=z_{\{2,2\}}^{2}$ hold exactly. We chose parameters that generate slightly different values in order to avoid confusion.
} 
- If $N^{1}>N^{2}$, then there will be $N^{2}$ optimal mixed developments with $\left(p_{1}^{\{1,2\}}, p_{2}^{\{1,2\}}\right)=(1.6178,4.1024)$ and $\frac{1}{2}\left(N^{1}-N^{2}\right)$ type $\{1,1\}$ developments with $z^{\{1,1\}}=2.5$ and $p^{\{1,1\}}=2.5$. That is, type 2 is scarce, so the type 2 consumers get all rent generated by mixed developments.

- If $N^{1}<N^{2}$, then there will be $N^{1}$ optimal mixed development with $\left(p_{1}^{\{1,2\}}, p_{2}^{\{1,2\}}\right)=(0.1506,5.5696)$ and $\frac{1}{2}\left(N^{2}-N^{1}\right)$ type $\{2,2\}$ developments with $z^{\{2,2\}}=2.5208$ and $p^{\{2,2\}}=2.5208$. In this case, type 1 consumers are scarce and get all rent.

- If $N^{1}=N^{2}$ happens to hold (by coincidence), then there will be a continuum of equilibria with $p_{1}^{\{1,2\}}+p_{2}^{\{1,2\}}=5.7202$ and $4.1024 \leq$ $p_{2}^{\{1,2\}} \leq 5.5696$, but only mixed developments exist in all equilibria.

Note that we can support each equilibrium allocation by an extended hedonic price equilibrium. Since (i) the allocation in the table for each case is the profit-maximizing allocation and (ii) it also achieves zero profit for entrepreneurial developers, if a developer offers any other allocation then it is not more profitable if the offered prices of houses are attractive to consumers. Let

$$
\tilde{p}_{1}(z)=\max \left\{v^{1}\left(z_{1}\right)-U^{1 *}, v^{2}\left(z_{1}\right)+g^{2}\left(z_{2}\right)-U^{2 *}\right\}
$$

and

$$
\tilde{p}_{2}(z)=\max \left\{v^{1}\left(z_{2}\right)-U^{1 *}, v^{2}\left(z_{2}\right)+g^{1}\left(z_{1}\right)-U^{2 *}\right\},
$$

where $z=\left(z_{1}, z_{2}\right)$. That is, $\left(\tilde{p}_{1}(z), \tilde{p}_{2}(z)\right)$ is the highest possible price vector a land developer can charge to attract any type of consumers. However, we know that the maximum profit a land developer can earn is zero by providing any kind of development that can attract consumers. Thus, for all $z, \tilde{p}_{1}\left(z_{1}\right)+\tilde{p}_{2}\left(z_{2}\right) \leq C(z)=z_{1}+z_{2}$ must hold. Thus, this price function supports our entrepreneurial equilibrium, and it is an extended hedonic price function. Similarly, it is easy to see that if there is an extended hedonic price equilibrium then we can create an entrepreneuiral equilibrium.

\section{General Model}

\subsection{Overview of the model}

The model assumes that there is only one private good as a numeraire good except for housing goods. A housing development is characterized by three 
things: the number of units in the development, a public facility (a list of local public goods such as landscaping), and the characteristics of each unit. We assume that there is only one type of location: say, there are many similar suburbs. We can easily introduce many different types of location. The number of units in a development is denoted by an integer $H$, and housing units are denoted by $h \in\{1, \ldots, H\}$. A facility $e$ is a discrete local public project in the development, such as a nicely landscaped human-made pond, a common field, and/or a playground if it is a suburban development; or the number of stories of the building, the design of the building, and/or fitness facilities such as swimming pools, treadmills, and exercise bikes, if it is a condominium complex in a city. The set of feasible facilities is denoted by $E$. To allow for inaction by land developers, we assume $\emptyset \in E$. Each housing unit $h$ has quality $z_{h} \geq 0 .{ }^{7}$ We allow that the " $h$ th" unit itself has specific characteristics: it may be facing a human-made pond in a suburban development, or it may be located on the top floor or on the scenic side of the building in an inner-city condo. Let $z=\left(z_{1}, \ldots, z_{h}, \ldots, z_{H}\right)$ be the profile of housing characteristics in a development. Consumers have preferences over all possible characteristics of the units $(e, H, z, h)$. Here, choosing $(e, H, z, h)$ means "living in the $h$ th unit of development with characteristics $(e, H, z)$." The cost to produce a development $(e, H, z)$ is denoted by $C^{e H}(z)$, where $C^{e H}: \mathbb{R}_{+}^{H} \rightarrow \mathbb{R}_{+}$is a real-valued function for all fixed $e$ and $H$. We also assume that provision of no facility and no physical houses $(H=0)$ is always costless $C^{\emptyset}=0$ (inaction: no provision, then no cost). That is, the developers can earn at least zero profit.

\subsection{Consumers}

There is a finite number of consumer types. The set of all types is denoted by $\Theta$, and its representative element is $\theta \in \Theta$. A type $\theta$ consumer is endowed with numeraire good $I^{\theta}>0$ (a composite good) and has a utility function $u^{\theta}=u^{\theta}\left(x, z_{h}, z_{-h}, e, H, h\right)$ that describes type $\theta$ consumer's utility when she chooses unit $h \in\{1, \ldots, H\}$ in a development with characteristics $(e, H)$ and housing quality profile $z=\left(z_{h}, z_{-h}\right) \in \mathbb{R}_{+}^{H}$, where $z_{h}$ denotes the characteristics of housing unit $h$, and $z_{-h}$ is the list of characteristics of all other $H-1$

\footnotetext{
${ }^{7}$ It is easy to generalize one-dimensional quality to multidimensional characteristics $z_{h}=\left(z_{h 1}, \ldots, z_{h K}\right) \in \mathbb{R}_{+}^{K}$ : these can represent the unit size (square feet), the size of the lot, and the quality of the kitchen and bathrooms, etc., of unit $h$.
} 
houses. This setup allows for consumption externalities in housing consumption: consumers are allowed to care about their neighbors' housing types as well as their own housing type. Related to housing externalities, note that we are assuming anonymity of consumption externalities: consumers do not care about the (preference) types of their neighbors. They only care about the characteristics of the housing units in the same development. That is, as long as a consumer's house characteristics and the other consumers' house characteristics are the same, she does not care who her neighbors are. We also assume that no house $\emptyset$ is always available for consumers. This may be interpreted as the consumer living in a self-made cabin. In this case, type $\theta$ consumer's utility is $u^{\theta}\left(I^{\theta}, \emptyset\right)$. Each type $\theta \in \Theta$ has a population measure $N^{\theta}>0$ with $\sum_{\theta \in \Theta} N^{\theta}=1$.

\subsection{Land Developers}

There is a continuum of land developers, and they can be considered as consumers or absentee landlords. ${ }^{8}$ We assume that each land developer can supply only one development. A land developer chooses the characteristics of her development $(H, e, z, p)$ freely, where $p=\left(p_{1}, \ldots, p_{H}\right) \geq 0$ is a price vector of houses in the development. She maximizes her profit

$$
\sum_{h=1}^{H} p_{h}-C^{e H}(z) .
$$

To sell a unit $h$ (profitably), the developer needs to target a type of consumer as a buyer for each unit $h \in\{1, \ldots, H\}$. She should set price $p_{h}$ to give the targeted buyer just the market utility: the same utility that can be achieved elsewhere (in equilibrium, each type of consumer gets the same utility level). Let us define an assignment vector $\alpha=\left(\alpha_{1}, \ldots, \alpha_{H}\right) \in \Theta^{H}$, where $\alpha_{h}$ describes the type that is assigned to unit $h$. A type of development is described by $\gamma$, and its policy is described by a vector $\left(e^{\gamma}, H^{\gamma}, z^{\gamma}, p^{\gamma}, \alpha^{\gamma}\right)$. In a type $\gamma$ development, given its assignment vector $\alpha^{\gamma}=\left(\alpha_{1}^{\gamma}, \ldots, \alpha_{H^{\gamma}}^{\gamma}\right)$, each household $h=1, \ldots, H^{\gamma}$ consumes $x_{h}^{\gamma}=I^{\alpha_{h}^{\gamma}}-p_{h}^{\gamma}$ numeraire good. Thus, the numeraire consumption vector in a type $\gamma$ development is denoted by $x^{\gamma}=\left(x_{1}^{\gamma}, \ldots, x_{H^{\gamma}}^{\gamma}\right)$. That is, a consumption allocation at a type $\gamma$ development is a pair

\footnotetext{
${ }^{8}$ In the equilibrium, land developers earn zero profits, so who develops the land is not important.
} 
$\left(x^{\gamma}, z^{\gamma}\right) .{ }^{9}$ The set of all feasible types of development is denoted by $\Gamma$. The assignment $\alpha^{\gamma}$ plays an important role in the following analysis in order to describe feasibility constraints and targeted types of development type $\gamma$, etc. We assume that land developers obtain their utility only from numeraire good consumption, although, in our model, land developers do not earn profits in equilibrium.

\subsection{Allocations}

To define an allocation, we impose assumptions on the populations of individuals and club memberships. Let $n^{\theta}(\gamma) \equiv\left|\left\{h \in\left\{1, \ldots H^{\gamma}\right\}: \alpha_{h}=\theta\right\}\right|$ be the number of type $\theta$ consumers in a type $\gamma$ development.

Uniformly Bounded Development Sizes (UB). Each development has at most $\bar{H}<\infty$ housing units: i.e., $H \leq \bar{H}<\infty$ for all developments.

Measurement Consistency (MC). Suppose that there is a Lebesgue measure $\mu^{\prime}(\gamma)$ of clubs of the same type $\gamma$ that have the same population composition $\left(n^{\theta}(\gamma)\right)_{\theta \in \Theta} \in \mathbb{Z}_{+}^{\Theta}$. Then, the total population of type $\theta$ consumers who belong to clubs of type $\gamma$ is $\mu^{\prime}(\gamma) \times n^{\theta}(\gamma)$ for all $\theta \in \Theta$.

Assumption UB is standard in order to avoid integer problems that result in the nonexistence of equilibrium. Assumption UB is key for our result. Assuming finiteness of residents in each jurisdiction together with a continuum of consumers (and finite types) guarantees the dissolution of integer problems. Note that UB together with a continuum of population necessarily implies that there is a continuum of jurisdictions in the economy (Ellickson et al. 1999; Allouch et al. 2008). UB has been formulated in various ways with various labels. However, the simplest way to state it (for our purposes) is as above. Wooders (1980) was the first to introduce this assumption in a large finite economy. Kaneko and Wooders (1986) extended it in a continuum

\footnotetext{
${ }^{9}$ In this definition, each development in the same type assigns the same consumption allocation. Obviously, we can assign different consumption allocations to the same development types in general. More general definitions using the "distribution approach" can be found in Mas-Colell (1984) or Zame (2007). However, notice that we will need convex preferences for our theorem, so we essentially lose nothing by imposing symmetric treatment of the same type developments.
} 
economy in order to dismiss a small-scale integer problem. The last assumption, MC, is a technical assumption in a continuum economy. It requires that the composition of a finite population aggregates nicely to a composition of a continuum of population, which is also introduced by Kaneko and Wooders (1986). We use this assumption in the proof of our propositions in order to aggregate consumers' jurisdiction and consumption choices. We assume UB and MC throughout the paper as in Konishi (2008).

A development allocation is a measure $\mu: \Gamma \rightarrow \mathbb{R}_{+}$such that $\mu(\gamma)$ is a Lebesgue measure of type $\gamma$ club such that $\int_{\Gamma} n^{\theta}(\gamma) d \mu=N^{\theta}$ for all $\theta \in \Theta$. A feasible allocation is a list of development and consumption allocations $(\mu,(x, z))$, such that

$$
\int_{\Gamma}\left(\sum_{h=1}^{H^{\gamma}} x^{\gamma}+C^{e^{\gamma} H^{\gamma}}\left(z^{\gamma}\right)\right) d \mu \leq \sum_{\theta \in \Theta} N^{\theta} I^{\theta} .
$$

An allocation is an equal treatment, for all $\theta \in \Theta$, if $u^{\theta}\left(x_{h}^{\gamma}, z^{\gamma}, e^{\gamma}, H^{\gamma}, h\right)=\bar{u}^{\theta}$ for all $h$ with $\alpha_{h}^{\gamma}=\theta=N^{\theta}$ holding almost everywhere for some $\bar{u}^{\theta} \in \mathbb{R}$.

\subsection{Consumer's Choice among Available Housing Units}

A type $\theta$ consumer's utility from choosing development $\gamma$ and its housing unit $h$ is

$$
U^{\theta}(\gamma, h)=u^{\theta}\left(I^{\theta}-p_{h}^{\gamma}, z_{h}^{\gamma}, z_{-h}^{\gamma}, e^{\gamma}, H^{\gamma}, h\right) .
$$

Note that $\alpha_{h}^{\gamma}=\theta$ is not required in the above. Even if unit $h$ is catered to another type $\theta^{\prime}$, type $\theta$ consumer is allowed to purchase the unit if she wants to. Each consumer chooses the best housing unit that is available in the market.

\subsection{Entrepreneurial Equilibrium}

Our equilibrium concept is based on an idea from Rothschild and Stiglitz (1976). ${ }^{10}$ The equilibrium concept involves three things: (i) consumers are

\footnotetext{
${ }^{10}$ Our equilibrium concept is also related to Rothschild and Stiglitz (1976), since land developers cannot discriminate between consumers by their types while developers know the distribution of consumer types. Rothschild and Stiglitz (1976) show that there may not be equilibrium and equilibrium may not be efficient in their insurance market, while
} 
free to choose a club type and a policy among the ones existing in the market; (ii) club managers cannot distinguish applicants' types; and (iii) club managers are entrepreneurs, and in equilibrium, there is no profit opportunity by offering nonexisting club types. ${ }^{11}$ Recall a type $\gamma \in \Gamma$ club corresponds to the list of characteristics $\left(e^{\gamma}, H^{\gamma}, z^{\gamma}, p^{\gamma}, \alpha^{\gamma}\right)$.

Definition. An entrepreneurial equilibrium is a list of $\left(\Gamma^{*}, \mu^{*},\left(e^{\gamma}, H^{\gamma}, z^{\gamma}, p^{\gamma}, \alpha^{\gamma}\right)_{\gamma \in \Gamma}\right)$ such that

1. (Optimal House Choice)

For all $\theta \in \Theta$, all $\gamma \in \Gamma^{*}$, and all $h$ with $\alpha_{h}^{\gamma}=\theta$,

$$
U^{\theta}(\gamma, h)=\max _{\gamma^{\prime} \in \Gamma^{*}, h \in\left\{1, \ldots, H^{\gamma^{\prime}}\right\}} U^{\theta}\left(\gamma^{\prime}, h^{\prime}\right),
$$

2. (Population Consistency)

For all $\theta \in \Theta, \int_{\gamma \in \Gamma^{*}} n(\theta) d \mu^{*}=N^{\theta}$ holds,

3. (Zero Profit Condition for Existing Developments)

$\sum_{h=1}^{H^{\gamma}} p_{h}^{\gamma}-C^{e^{\gamma} H^{\gamma}}\left(z^{\gamma}\right)=0$ holds almost everywhere in $\Gamma^{*}$,

4. (Exhausted Profit Opportunities)

For all $\gamma^{\prime} \in \Gamma \backslash \Gamma^{*}$, if $\sum_{h=1}^{H^{\gamma^{\prime}}} p_{h}^{\gamma^{\prime}}-C^{e^{\gamma^{\prime}} H^{\gamma^{\prime}}}\left(z^{\gamma^{\prime}}\right)>0$ then such a development is infeasible in the sense that it cannot fill at least one housing unit: i.e., there exists $h \in\left\{1, \ldots, H^{\gamma^{\prime}}\right\}$ such that

$$
U^{\alpha_{h}^{\gamma^{\prime}} *}>U^{\alpha_{h}^{\gamma^{\prime}}}\left(\gamma^{\prime}, h\right),
$$

where $U^{\theta *}$ is type $\theta^{\prime}$ 's equilibrium utility $\left(U^{\theta *}=U^{\theta}\left(\gamma, h^{\prime}\right)\right.$ for all $\gamma \in \Gamma^{*}$ and all $h^{\prime}$ with $\alpha_{h^{\prime}}=\theta$ ).

Note that the commodity market clears automatically by developments' zero profit conditions since there is only one private good. The key to the

we show both existence and efficiency. The difference is that we assume consumption externalities (thus consumer types do not matter: only consumption behavior matters), while in Rothschild and Stiglitz (1976), consumer types themselves matter.

${ }^{11}$ Konishi (2008) uses a similar equilibrium concept to achieve efficiency of equilibrium in a local public goods economy. However, in Konishi (2008), each jurisdiction has a homogeneous population by the nature of the model as in Tiebout (1956). In this paper, we deal with mixed clubs to achieve efficiency. 
above definition is that we distinguish between $\Gamma^{*}$ (existing development types) and $\Gamma \backslash \Gamma^{*}$ (unobserved club types). ${ }^{12}$ By condition $2, \mu^{*}\left(\Gamma \backslash \Gamma^{*}\right)=0$ must hold. Note that it is not enough to say $\mu^{*}\left(\Gamma \backslash \Gamma^{*}\right)=0$, since as long as a type of development exists (even with zero measure), consumers may be attracted to the development type. We need to say that there is no development for $\gamma \in \Gamma \backslash \Gamma^{*}$.

We also assume that land developers are entrepreneurial. Although land developers can easily observe how profitable a policy is as long as there is a club that chooses that policy, if a policy is not chosen by any club, the managers need to estimate how profitable it would be by utilizing their information on consumers' utilities (in the manner of Rothschild and Stiglitz 1976). This entrepreneurship is captured by equilibrium condition 4. By contrast, if managers are passive, there can be many inefficient equilibria if no developer chooses potentially profitable policies that go unobserved. We assume that there is no market for unobserved policies $\left(\gamma \in \Gamma \backslash \Gamma^{*}\right)$. Our condition 4 is similar to a condition in the equilibrium concept by Rothschild and Stiglitz (1976).

\section{The Main Result}

Before stating our result, let us define Pareto-efficient (equal treatment) allocation. Suppose that a feasible allocation $(\mu, \alpha,(x, z))$ achieves an equal treatment utility level $\bar{u}=\left(\bar{u}^{\theta}\right)_{\theta \in \Theta}$ : i.e., for all $\theta \in \Theta$, and all $\gamma \in \Gamma$ with $\mu(\gamma)>0$ and all $h=1, \ldots, H^{\gamma}$ such that $\alpha_{h}^{\gamma}=\theta, u^{\theta}\left(x_{h}^{\gamma}, z_{h}^{\gamma}, z_{-h}^{\gamma}, e^{\gamma}, H^{\gamma}, h\right)=\bar{u}^{\theta}$. An equal treatment allocation $(\mu, \alpha,(x, z))$ is Pareto efficient if there is no feasible allocation $\left(\mu^{\prime}, \alpha^{\prime},\left(x^{\prime}, z^{\prime}\right)\right)$ such that

$$
\mu^{\prime}\left(\left\{\gamma \in \Gamma: u^{\theta}\left(x_{h}^{\gamma^{\prime}}, z_{h}^{\gamma^{\prime}}, z_{-h}^{\gamma \prime}, e^{\gamma}, H^{\gamma}, h\right) \geq \bar{u}^{\theta} \forall h \text { with } \alpha_{h}^{\gamma}=\theta \forall \theta \in \Theta\right\}\right)=1,
$$

and

$$
\mu^{\prime}\left(\left\{\gamma \in \Gamma: u^{\theta}\left(x_{h}^{\gamma \prime}, z_{h}^{\gamma \prime}, z_{-h}^{\gamma \prime}, e^{\gamma}, H^{\gamma}, h\right)>\bar{u}^{\theta} \exists h \text { with } \alpha_{h}^{\gamma}=\theta \exists \theta \in \Theta\right\}\right)>0 .
$$

\footnotetext{
${ }^{12}$ Bewley (1981) and Wooders (1989) also proposed equilibrium concepts in which only existing clubs are priced. Their equilibria achieve efficiency through potential coalitional deviations by consumers (instead of managers' entrepreneurship: see Gersbach and Haller 2010 and Gersbach, Haller, and Konishi 2012 as well). As a result, they assume that the deviating group knows each member's type when forming an agreement within it. In contrast, our entrepreneurial developers do not need to be able to distinguish consumers' types to form nonexisting developments.
} 
That is, if a positive measure of developments can improve the residents' utilities (recall that there are finitely many members in each development) without hurting others, then an equal-treatment allocation is not Pareto efficient.

The main result of our paper is stated below.

Theorem. There exists an entrepreneurial equilibrium, and every entrepreneurial equilibrium is Pareto efficient in the market for land developers under the following assumptions:

1. For all $\theta \in \Theta$, all $e \in E$, all $H \leq \bar{H}$, and all $h \in\{1, \ldots, H\}, u^{\theta}\left(x_{h}, z_{h}, z_{-h}, e, H, h\right)$ is continuous in $\left(x_{h}, z_{h}, z_{-h}\right)$ and strictly increasing in $x_{h}$ and $z_{h}$,

2. For all $\theta \in \Theta$, all $e \in E$, all $H \leq \bar{H}$, all $h \leq H$, all $x_{h} \in \mathbb{R}_{+}$, and all $z, z^{\prime} \in \mathbb{R}_{+}^{H}, u^{\theta}\left(x_{h}, z, e, H, h\right) \geq u^{\theta}\left(0, z^{\prime}, e, H, h\right)=u^{\theta}(0, \emptyset)$ (essentiality of private good consumption),

3. For all $\theta \in \Theta$, all $e \in E$, and all $H \leq \bar{H}, u^{\theta}\left(x_{h}, z, e, H, h\right)$ is weakly quasi-concave in $\left(x_{h}, z\right)$,

4. For all $H \leq \bar{H}$ and all $e \in E, C^{e H}(z)$ is nonnegative, continuous, and convex in $z$.

Assumption 1 is standard. Assumption 2 is also standard when the consumption set is not connected (indivisible commodities: see Mas-Colell 1977, Wooders 1978, and Ellickson 1979) for the spirit of this assumption). Assumption 3 requires quasi-concavity including $z_{-h}$ (neighbors' house sizes). Intuitively, this condition means that a development with more diversified house sizes is (weakly) less preferable to a consumer given that the size of her house is the same. It allows for consumers who do not care about the sizes of neighbors' houses. This is assumed in order to find a Pareto-optimal allocation in each development (finite population in each development). ${ }^{13}$ We need this assumption to deal with the consumption externalities within developments. This is the key difference from Ellickson et al (1999) and Allouch et al (2009). Assumption 4 ensures a compact, convex feasible set of housing

\footnotetext{
${ }^{13}$ Specifically, we use the Shafer-Sonnenschein (1975) mapping for the existence of Pareto-efficient equilibrium. Thus, we need the intersection of upper contour sets to be open graph (continuity) and (semi) convex-valued (convex preferences).
} 
profiles for each $(e, H)$. Nonemptiness of the feasible set of housing profiles may not be assured for all $(e, H)$, but we can avoid such a technical problem by Assumption 2 together with an innocuous assumption $C^{\emptyset}=0$ (inaction).

The strategy to prove this theorem is as follows. First, we show that all entrepreneurial equilibria are Pareto efficient. Second, defining a Paretoefficient allocation with a private good market equilibrium and voting with feet, we show that there exists such allocation, and that every such allocation can be (essentially) supported as entrepreneurial equilibrium.

Proposition 1. Every entrepreneurial equilibrium is Pareto efficient.

Proof. This follows directly from Condition 4 of the definition of entrepreneurial equilibrium. Suppose that there is a Pareto-superior feasible allocation. This means that there exists a development type (with a positive measure) such that (i) it has members who have strictly higher utilities, and it satisfies budget balance (due to feasibility). Let the development type have facility $e$, population $H$, type assignment $\alpha=\left(\alpha_{1}, \ldots, \alpha_{H}\right) \in \Theta^{H}$, and consumption vector $\left(x_{h}, z_{h}\right)_{h=1}^{H}$ such that (i) $u^{\alpha_{h}}\left(x_{h}, z_{h}, z_{-h}, e, H, h\right)>U^{\alpha_{h} *}$ for all $h=1, \ldots, H$, and (ii) $\sum_{h=1}^{H} x_{h}+C^{e H}(z) \leq \sum_{h=1}^{H} I^{\alpha_{h}}$, where $U^{\theta *}$ is the equilibrium utility level for type $\theta$. By the continuity of utility functions, there exists $\epsilon>0$ such that $u^{\alpha_{h}}\left(x_{h}-\epsilon, z_{h}, z_{-h}, e, H, h\right)>U^{\alpha_{h} *}$ for all $h=1, \ldots, H$. Thus, if a club manager proposes house price $p_{h}=I^{\alpha_{h}}-x_{h}+\epsilon$ for all $h=1, \ldots, H$, then at least type $\alpha_{h}$ consumers are attracted by the offer (some other type may also want the unit, but the land developer does not care about whom to sell to), and the land developer can make a positive profit.

Note that a deviating land developer does not care about which type of consumers fill the housing units. She cares only about all the houses in the development being filled. This is because of anonymity in congestion. Thus, the above deviation is sufficient to show the Pareto optimality of entrepreneurial equilibrium. The existence of entrepreneurial equilibrium is involved, so we defer the proof to the appendix.

Our notion of equilibrium is a static one, and developers can earn no profit in the equilibrium. However, the Pareto-efficient allocation is achieved only through developers' entrepreneurship. Whenever there is a better type of development for consumers, there is a profit opportunity for developers. In the long run, all profit opportunities disappear, and the Pareto-optimal 
allocation is realized. In this sense, consumers benefit from developers' entrepreneurship.

We need to show the existence of entrepreneurial equilibrium in order to complete the proof of Theorem 1 .

Proposition 2. There exists an entrepreneurial equilibrium.

The proof of Proposition 2 is involved and is provided in the appendix. Here, we will provide a brief sketch of it. We first introduce an idealized economy with prices for all feasible developments $\gamma \in \Gamma^{F}$. For each $\gamma$, assuming that residents' types occupying the units are determined by $\alpha^{\gamma}$, we assign a Pareto-efficient allocation (a Pareto-efficient profile of numeraire consumption and housing characteristics) in each feasible $\gamma$ by a mapping introduced by Shafer and Sonnenschein (1975). For each type of consumer, let her choose her most-preferred units (numeraire consumption and the characteristics of the unit and other units in the development) in all types of developments. Based on their best responses, we construct a population mapping (Konishi 1996). These two mappings together construct a fixed-point mapping, and the fixed point is shown to be a (globally) Pareto-efficient allocation that has a price support by a complete price system. We then show that the complete price equilibrium is an entrepreneurial equilibrium. This line of the proof is developed by Konishi (2010), but we extend it here to accommodate more general consumption externalities and joint production technologies. One of the advantages of our method is that we do not need to deal with a continuum of commodities and their prices explicitly in the fixed-point mapping we only need Kakutani's fixed-point mapping, although we have a continuum of potential commodities. The advantage of our method is that we need only an elementary finite-dimensional fixed-point theorem despite the fact that the housing characteristic space is infinite-dimensional.

\section{Equivalence with Extended Hedonic Price Equilibrium}

As a corollary of Theorem 1, we can provide a rigorous version of Rosen's assertion: the existence and optimality of hedonic price equilibrium. Rosen (1974) assumes that no consumption externalities are present. Formally, Rosen assumes that there is no (common) facility $e$, and no consumption 
externalities. ${ }^{14}$ Rosen also assumes that $C^{H}(z)$ is a convex function without feasibility constraint. With a (strict) convex cost function, Pareto-efficient developments are all homogeneous if $H$ is fixed, so we assume that $H$ is fixed as well. ${ }^{15}$ In this economy, Rosen defines a hedonic price system $p(z)$ that is a price function on housing quality (characteristics): $p(z)$ is the price of housing unit with characteristics $z$. Although not formally defined in his paper, Rosen's equilibrium concept can be written as follows: a hedonic price equilibrium is a list of hedonic price system $p(z)$, measure $\mu$, and $\left(z^{\theta}\right)_{\theta \in \Theta} \in$ $\mathbb{R}_{+}^{\Theta}$ such that (i) $z^{\theta}=\arg \max _{z} u^{\theta}\left(I^{\theta}-p(z), z\right)$ for all $\theta \in \Theta$, (ii) $p(z) \leq \frac{C^{H}(z)}{H}$ for all $z \in \mathbb{R}_{+}$, (iii) $p(z)=\frac{C^{H}(z)}{H}$ for all $z \in \mathbb{R}_{+}$with $\mu(z)>0$, and (iii) $\mu(z)>0$ only if there exists $\theta \in \Theta$ such that $z=z^{\theta}$. We can show that the set of Rosen's hedonic price equilibrium allocations is equivalent to the one of entrepreneurial equilibrium allocations when there are no consumption externalities. However, we can extend Rosen's hedonic equilibrium to allow for joint production and consumer externalities by using a complete price system in the following manner. Denote the set of all feasible developments $(e, H, z)$ by $\Omega$. Let a complete price system $\tilde{p}:(e, H, z) \longmapsto\left(p_{1}, \ldots, p_{H}\right)$. That is, $\tilde{p}_{h}(e, H, z)$ is the price of unit $h \in\{1, \ldots, H\}$ (with characteristics $z_{h}$ ) at a development of which the housing unit profile is $z=\left(z_{1}, \ldots, z_{H}\right)$ and facility is $e$. Price function $\tilde{p}$ is defined for all possible developments (complete price system). Let us denote the distribution of development by Lebesgue measure $\tilde{\mu}$ on $\Omega$ with $\tilde{\mu}(\Omega)=1$. Let type $\theta$ consumer's utility under optimal choice be

$$
\tilde{U}^{\theta}(\tilde{p})=\max _{(e, H, z), h \in\{1, \ldots, H\}} u^{\theta}\left(I^{\theta}-\tilde{p}_{h}(e, H, z), z, e, H, h\right)
$$

Denote the set of all possible housing units $(e, H, z, h)$ where $h \in\{1, \ldots, H\}$ denoted by $\Omega^{H}$, and describe type $\theta$ 's choice by Lebesgue measure $\tilde{\nu}^{\theta}$ on $\Omega^{H}$. For all $\theta \in \Theta$, measure $\tilde{\nu}^{\theta}$ satisfies $\tilde{\nu}^{\theta}\left(\Omega^{H}\right)=N^{\theta}$. To avoid technical difficulties, we assume that in the equilibrium allocation for each $(e, H)$ there is at most one type of housing unit profile $z \in \mathbb{R}_{+}^{H \times K}$ : i.e., for all $(e, H) \in$ $E \times\{1, \ldots, \bar{H}\}$, we have $\tilde{\mu}\left(\left\{\left(e^{\prime}, H^{\prime}, z^{\prime}\right) \in \Omega \mid\left(e^{\prime}, H^{\prime}\right)=(e, H)\right.\right.$ and $\left.\left.z^{\prime} \neq z\right\}\right)=$

\footnotetext{
${ }^{14}$ As mentioned before, we can introduce multiple characteristics to each house at no cost but with notational complexity.

${ }^{15}$ Rosen (1974) allows that the optimal number of units $H$ is dependent on $z$. This can be interpreted as the claim that $H$ can be chosen freely. However, if this were the case, his claim that the optimal house characteristics in a development are uniform would not hold in general.
} 
0. The extended hedonic price equilibrium is described as follows.

Definition. An extended hedonic price equilibrium is a list of $(\tilde{\mu}, \tilde{p}, \tilde{\nu})$ such that

1. (Optimal House Choice)

For all $\theta \in \Theta$, for all $(h, e, H, z) \in \Omega^{H}$ with $\tilde{\nu}^{\theta}(h, e, H, z)>0$,

$$
u^{\theta}\left(I^{\theta}-\tilde{p}_{h}(e, H, z), z, e, H, h\right)=\tilde{U}^{\theta}(\tilde{\mu}, \tilde{p}, \tilde{\nu}),
$$

2. (Population Consistency)

For all $(e, H, z) \in \Omega$ with $\tilde{\mu}(e, H, z)>0$, and all $h \in\{1, \ldots, H\}$, we have

$$
\tilde{\mu}(e, H, z)=\sum_{\theta \in \Theta} \tilde{\nu}^{\theta}(e, H, z, h),
$$

3. (Zero Profit Condition)

For all $(e, H, z) \in \Omega$ with $\tilde{\mu}(e, H, z)>0$ all $h=1, \ldots, H$,

$$
\sum_{h=1}^{H} p_{h}(e, H, z)=C^{e H}(z) \text {, }
$$

4. (Profit Maximization)

For all $(e, H, z) \in \Omega$,

$$
\sum_{h=1}^{H} p_{h}(e, H, z) \leq C^{e H}(z) .
$$

Proposition 3. The set of extended hedonic price equilibrium allocations is equivalent to that of entrepreneurial equilibrium allocations.

From the definition, the proof is obvious, so it is omitted. As corollaries of Theorem 1, we have the following.

Corollary 1. There exists an extended hedonic price equilibrium, and every extended hedonic price equilibrium is Pareto efficient.

Corollary 2. ${ }^{16}$ In Rosen's domain, there exists a hedonic price equilibrium, and every hedonic price equilibrium is Pareto efficient.

\footnotetext{
${ }^{16}$ In this domain, we can actually drop convex preferences (in consumers' own consumption vectors). See Ellickson et al. (1999) and Allouch et al. (2009). As we mentioned before, with local externalities, our proof of Theorem 1 cannot dispense convex preferences.
} 


\section{Conclusion}

Regarding new developments by land developers in suburbs as a source of competition among jurisdictions for residents, Tiebout (1956) discussed the idea that jurisdictional competition will lead to a Pareto-efficient allocation. His predictions of this mechanism are consumer sorting and homogeneous jurisdictions. In this paper, we allow joint production and consumption externalities within developments, and show that if land developers actively seek profits by catering to the needs of each type of consumer, then the first best is still achieved as a result of the competitive market, although the homogeneity of consumers in each development is lost. This implies that the key mechanism of the Tiebout process that achieves efficiency is not segregation of consumer types. We also show that our equilibrium is equivalent to an extended version of Rosen's (1974) hedonic price equilibrium - an equilibrium in which each characteristic of a house in each type of development characteristic has a market price.

In this paper, we assumed that consumers do not care about whether their neighborhood houses are occupied or not: they care only about the profile of housing characteristics in the development. However, perhaps a consumer who purchased the most prestigious house in a development would feel unhappy if the other houses are not occupied. We can allow for such preferences by letting type $\theta$ 's utility function be denoted by $u^{\theta}\left(x, z_{h}, z_{-h}, e, H, h ; b\right)$, where $b_{h^{\prime}} \in\{0,1\}$ for all $h^{\prime} \neq h$ denotes if unit $h^{\prime}$ is occupied or not (0 and 1 represent "empty" or "occupied"). It is natural to assume that type $\theta$ is happier if there are fewer empty houses in the neighborhood. However, then, her belief about house occupancy in the neighborhood influences her decision to take the house or not. This is a coordination problem: if potential residents believe that the development will be empty, then the land developer may become reluctant to provide such a development. If this happens, a suboptimal allocation may persist. In contrast, if a consumer is optimistic about the neighborhood's houses being occupied, then she will be willing to move into the development as long as her house would give her a higher utility than her current house in a different development. Let $\beta_{\gamma}: H[\gamma] \rightarrow\{0,1\}$ be each consumer's expectation on the occupancy of houses in development $\gamma$. We say that consumers' expectations are optimistic, when for all $\gamma \in \Gamma, \beta_{\gamma}(h)=1$ holds for all $h \in\{1, \ldots, H[\gamma]\}$ if and only if $U^{\alpha[\gamma](h)}(\gamma, h, \mathbf{1}) \geq U^{\alpha[\gamma](h) *}$ holds for all $h \in\{1, \ldots, H[\gamma]\}$. Thus, under optimistic expectations, (i) as long as all housing units are weakly more preferable than the ones prevailing in 
the market, the developer expects that all houses will be sold; and (ii) as long as a consumer finds a weakly more preferable housing unit, assuming that all housing units of a development will be occupied, she will take it. Thus, under optimism, developers would be willing to provide new types of developments as long as there is an opportunity for profit, and indeed the optimistic expectation proves to be true. ${ }^{17}$

\section{Appendix}

In this appendix, we prove Proposition 2 (the existence of entrepreneurial equilibrium). We first construct a Pareto-efficient allocation with free mobility, and we then show that it is indeed an entrepreneurial equilibrium. A type $d$ potential development is a list of the facility profile, assignment mapping, and population $d=\left(e^{d}, \alpha^{d}, H^{d}\right) \in \mathcal{D}$, where $\alpha^{d}=\left(\alpha_{1}^{d}, \ldots, \alpha_{H^{d}}^{d}\right) \in \Theta^{H}$. The set of all potential developments $\mathcal{D}$ is a finite set, since $E$ and $\bar{H}$ are both finite. ${ }^{18}$ Since $\emptyset \in E$ and $H=1$ is allowed, there is an empty development $\emptyset \in \mathcal{D}$ with $C^{\emptyset}=0$. This can be regarded as an outside option for consumers: a consumer can simply consume her own numeraire endowment entirely. We assign a consumption vector for each type of potential development. A symmetric consumption allocation for $d=\left(e^{d}, \alpha^{d}, H^{d}\right) \in \mathcal{D}$ is a vector $\left(x_{h}^{d}, z_{h}^{d}\right)_{h=1}^{H^{d}} \in \mathbb{R}_{+}^{2 H^{d}}$. The term "symmetry" applies since we assign the same intradevelopment allocation to all developments of the same type. Now, we define social equilibrium. Note that consumption vector $\left(x_{h}^{d}, z_{h}^{d}\right)$ is consumed by type $\alpha_{h}^{d} \in \Theta$. Let $m \in \mathbb{R}_{+}^{\mathcal{D}}$ be the measures of potential clubs, and let $p^{d}=\left(p_{1}^{d}, \ldots, p_{H}^{d}\right) \in \mathbb{R}_{+}^{H^{d}}$ be a unit-dependent price vector for development $d \in \mathcal{D}$.

Definition. A social equilibrium is a list of $\left(p^{d *}, z^{d *}, m^{d *}\right)_{d \in \mathcal{D}}$ such that

\section{1. (Intradevelopment Pareto Efficiency)}

For all $d \in \mathcal{D}, \sum_{h=1}^{H^{d}} p_{h}^{d *} \geq C^{e^{d} H^{d}}\left(z^{d *}\right)$ holds, and there is no symmetric

\footnotetext{
${ }^{17}$ In contrast, if there are no externalities within developments (the original hedonic price model: Rosen 1974), or if local externalities are negative externalities in the population (Berglas's congestible facility model: Konishi 2010), expectations play no role, so the first welfare theorem does not require optimism.

${ }^{18}$ The difference between $d$ and $\gamma$ is that $\gamma$ contains members' consumption allocations $(x, z)$ as well. Thus, unlike $\mathcal{D}, \Gamma$ is an infinite set, which is harder to deal with.
} 
allocation for $d,\left(\hat{p}^{d}, \hat{z}^{d}\right)$ such that

$$
u^{\alpha_{h}^{d}}\left(I^{\alpha_{h}^{d}}-\hat{p}_{h}^{d}, \hat{z}^{d}, e^{d}, H^{d}, h\right)>\tilde{U}^{\alpha_{h}^{d} *}(d),
$$

and

$$
\sum_{h=1}^{H^{d}} \hat{p}_{h}^{d} \geq C^{e^{d} H^{d}}(\hat{z}),
$$

2. (Optimal Housing Unit Choice)

For all $d \in \mathcal{D}$ with $m^{*}(d)>0$ and all $\theta \in \Theta$ such that $\alpha_{h}^{d}=\theta$ for some $h=1, \ldots, H^{d}, \tilde{U}^{\theta *}(d) \geq \tilde{U}^{\theta *}\left(d^{\prime}, h^{\prime}\right)$ holds for all $d^{\prime} \in \mathcal{D}$, and all $h^{\prime}=1, \ldots, H^{d^{\prime}}$,

3. (Population Consistency)

For all $\theta \in \Theta, \int_{\gamma \in \Gamma^{*}} \tilde{n}^{\theta}(d) d \mu^{*}=N^{\theta}$,

where $\tilde{U}^{\theta *}(d, h)=u^{\theta}\left(I^{\theta}-p_{h}^{d *},\left(z_{h}^{d *}\right)_{h=1}^{H^{d}}, e^{d}, H^{d}, h\right), \tilde{U}^{\theta *}(d)=\tilde{U}^{\theta *}(d, h)$ when $\alpha_{h}^{d}=\theta$, and $\tilde{n}^{\theta}(d)=\left|\left\{h: \alpha_{h}^{d}=\theta\right\}\right|$.

We have the following propositions.

Proposition A1. There exists a social equilibrium.

Using Shafer and Sonnenschein (1975) for intradevelopment Pareto efficiency, ${ }^{19}$ and population mapping based on consumers' optimal location choice, we can find a social equilibrium by using Kakutani's theorem (finite $\mathcal{D}$ and $\Theta$ ). In order to apply Shafer and Sonnenschein, we use quasi-concavity of utility functions.

Proof. We will construct a fixed-point mapping that (eventually) achieves Pareto-efficient allocation for all potential developments $d=\left(e^{d}, \alpha^{d}, H^{d}\right) \in$ $\mathcal{D}$. Note that $\mathcal{D}$ is a finite set. Numeraire consumption and housing consumption are separately determined, but in the fixed point, they achieve Pareto-efficient allocation together.

\footnotetext{
${ }^{19}$ Greenberg (1979) used the Shafer-Sonnenschein method to show the existence of a $q$-majority voting equilibrium (see Konishi 1996 for an application to the existence of voting equilibrium in a local public goods economy). When $q=\infty$, the $q$-majority voting rule coincides with the Pareto rule. Ray and Vohra (1997) directly apply the ShaferSonnenschein method to show the existence of a Pareto-optimal allocation.
} 
Let $\mathcal{P}^{d}: \mathbb{R}_{+}^{2 H^{d}} \times \Delta \rightarrow \mathbb{R}_{+}^{2 H^{d}}$ be a Pareto mapping such that

$$
\begin{gathered}
\mathcal{P}^{d}(x, z) \\
=\left\{(\tilde{x}, \tilde{z}) \in \mathbb{R}_{+}^{2 H^{d}}: u^{\alpha_{h}^{d}}\left(\tilde{x}_{h}, \tilde{z}, e^{d}, H^{d}, h\right)>u^{\alpha_{h}^{d}}\left(x, z, e^{d}, H^{d}, h\right) \forall \theta \in \Theta\right. \\
\text { and } \left.\sum_{h=1}^{H^{d}} \tilde{x}^{\alpha_{h}^{d}} \leq \sum_{h=1}^{H^{d}} I^{\alpha_{h}^{d}}-C^{e^{d} H^{d}}(\tilde{z})\right\} .
\end{gathered}
$$

There is only a finite number of types, and a finite intersection of open sets is open (relative to the feasibility set: the inequality in the last line). Let a compactified set of feasible profiles of housing qualities for $d \in \mathcal{D}$ be

$$
F^{d} \equiv\left\{(x, z) \in \mathbb{R}_{+}^{2 H^{d}}: \sum_{h=1}^{H^{d}} x_{h}+C^{e^{d} H^{d}}(z) \leq \sum_{h=1}^{H^{d}} I^{\alpha_{h}^{d}}\right\}
$$

We also artificially set $F^{d}=\{0\} \in \mathbb{R}_{+}^{2 H^{d}}$ for all $d \in \mathcal{D}$ with $C^{e^{d} H^{d}}(0)>$ $\sum_{h=1}^{H^{d}} I^{\alpha_{h}^{d}}$ : i.e., we assume that $z=0$ is feasible for development $d$ when it is infeasible. Assumption 2 (essentiality of private good) together with $C^{\emptyset}=0$ ensures that infeasible developments are not chosen by consumers in the fixed point. This set is nonempty, compact, and convex $\left(C^{e H}(z)\right.$ is continuous and convex). Thus, mapping $\mathcal{P}^{d}$ has an open graph (utility function is continuous) in the feasible set $F^{d}$. Let $U_{S S}^{d}: F^{d} \times F^{d} \rightarrow \mathbb{R}_{+}$ be a Shafer-Sonnenschein utility function constructed from $F^{d}$ such that $U_{S S}^{d}(x, z ; \tilde{x}, \tilde{z})=0$ if $(\tilde{x}, \tilde{z}) \notin \mathcal{P}^{d}(x, z)$, and $U_{S S}^{d}(x, z ; \tilde{x}, \tilde{z})$ is the distance between $(\tilde{x}, \tilde{z})$ and the topological boundary of $\mathcal{P}^{d}(x, z)$, otherwise (see Shafer and Sonnenschein 1975). This is a continuous function in its arguments.

Let $\delta^{d}: F^{d} \times \Delta \rightarrow F^{d}$ be such that

$$
\delta^{d}(x, z)=\arg \max _{(\tilde{x}, \tilde{z}) \in F^{d}} U_{S S}^{d}(x, z ; \tilde{x}, \tilde{z})
$$

This mapping $\delta^{d}$ is designed to find intradevelopment Pareto-efficient allocations as a fixed point of the mapping.

Let $\delta: \Pi_{d \in \mathcal{D}} F^{d} \rightarrow \Pi_{d \in \mathcal{D}} F^{d}$ be a product of $\delta^{d}$ s. Let $\operatorname{proj}_{z} \delta: \Pi_{d \in \mathcal{D}} F^{d} \rightarrow$ $\Pi_{d \in \mathcal{D}} F^{d}$ be a project of $\delta$ on utilizations of facility profile (dropping the numeraire consumption from all types in all potential developments). Let $\tilde{\delta}=\operatorname{proj}_{z} \delta$. 
Let $M \equiv\left\{m \in \mathbb{R}_{+}^{\mathcal{D}} \mid \sum_{d \in \mathcal{D}} m^{d} H^{d}=1\right\}$. This is the space of development distributions that are consistent with the population distribution over types. Let $\tilde{M} \equiv\left\{m \in \mathbb{R}_{+}^{\mathcal{D}} \mid \sum_{d \in \mathcal{D}} m^{d} H^{d}=1.1\right\}$. This set can be regarded as a "free entry condition" (note $\emptyset \in \mathcal{D}$ ). This is because a fraction of developers must choose to provide a trivial empty development (i.e., $e=\emptyset$ and $H=0$ ), which guarantees zero profit. This device guarantees zero profit in the fixed point of the mapping. Let

$$
\tilde{U}^{\theta}[d, h](x, z) \equiv u^{\theta}\left(I^{\theta}-\left(I^{\alpha[d](h)}-x_{h}(d)\right), z(d), e[d], H[d], h\right) .
$$

By type $\theta$ choosing a house $(d, h)$, she can consume numeraire by $I^{\theta}-$ $\left(I^{\alpha[d](h)}-x_{h}(d)\right)=I^{\theta}-p_{h}(d)$. Let $R^{\theta} \equiv\left\{r^{\theta} \in \mathbb{R}_{+}^{\Sigma_{d \in \mathcal{D}} H[d]} \mid \sum_{d \in \mathcal{D}, 1 \leq h \leq H[d]} r^{\theta}(d, h)=\right.$ $\left.N^{\theta}\right\}$. Let $\rho^{\theta}: \Pi_{d \in \mathcal{D}} \mathcal{F}[d] \rightarrow R^{\theta}$ be such that

$$
\begin{aligned}
& \rho^{\theta}(x, z) \\
= & \left\{r^{\theta} \in R^{\theta}: r^{\theta}(d, h)>0 \Rightarrow U^{\theta}[d, h](x, z) \geq U^{\theta}\left[d^{\prime}, h^{\prime}\right](x, z) \forall d^{\prime} \in \mathcal{D} \forall 1 \leq h^{\prime} \leq H\left[d^{\prime}\right]\right\} .
\end{aligned}
$$

Let $R \equiv \prod_{\theta \in \Theta} R^{\theta}$ and $\rho: \Pi_{d \in \mathcal{D}} \mathcal{F}[d] \rightarrow R$ be such that

$$
\rho(x, z)=\Pi_{\theta \in \Theta} \rho^{\theta}(x, z) .
$$

This is a population mapping that assigns each type of consumer to the holding units that offer the highest utilities. Let $Y \equiv\left\{y \in \mathbb{R} \times[-1,1]^{\Sigma_{d \in \mathcal{D}} H[d]}: \sum_{d \in \mathcal{D}} y(d, h)=0\right\}$. Let $\eta: \Pi_{d \in \mathcal{D}} X \times \mathcal{F}[d] \times R \times P \rightarrow Y$ be such that

$$
\eta(x, z, m)=\left(\sum_{\theta \in \Theta} \rho^{\theta}(x, z)-\prod_{d \in \mathcal{D}} m(d) \times \mathbf{1}_{H[d]}\right),
$$

where $\mathbf{1}_{H[d]}=(1)_{h=1}^{H[d]}$. Recall $N=\sum_{\theta \in \Theta} N^{\theta}=1$. So, the range of mapping $\eta$ is in $Y$. This is an excess demand mapping for each type of house in each development. Let $P \equiv[0, \bar{I}]^{\Pi_{d \in \mathcal{D}} H[d]}$, where $\bar{I}>\max _{\theta \in \Theta} I^{\theta}$. This is the set of housing price vectors.

The land developer's profit by providing type $d \in \mathcal{D}$ club is

$$
\pi[d](p(d))=\sum_{h=1}^{H[d]} p_{h}(d)-C[e[d], H[d]](z(d)) .
$$

Given land developers' profit-maximization behavior, if one type of development is profitable, all land developers are drawn to that type. Let $\mu: P \rightarrow \tilde{M}$ be such that

$$
\mu(p(d))=\left\{m \in \tilde{M} \mid m(d)>0 \Rightarrow d \in \arg \max _{d \in \mathcal{D}} \pi[d](p(d))\right\} .
$$


Let $\sigma: Y \rightarrow P$ be such that

$$
\sigma(y)=\arg \max _{p \in P} \sum_{d \in \mathcal{D}} p(d) y(d)
$$

This is a price mapping.

Finally, let $\beta: P \rightarrow \Pi_{d \in \mathcal{D}} \mathbb{R}_{+}^{H[d]}$ be such that $x_{h}^{\alpha[d]}(d) \equiv \max \left\{0, I^{\alpha[d]}-\right.$ $\left.p_{h}(d)\right\}$ for all $1 \leq h \leq H[d]$.

Our fixed-point mapping is a product of all the above mappings, $\beta, \tilde{\delta}, \mu$, $\eta$, and $\sigma$ :

$$
\varphi: \Pi_{d \in \mathcal{D}} \mathcal{F}[d] \times M \times Y \times P \rightarrow \Pi_{d \in \mathcal{D}} \mathcal{F}[d] \times M \times Y \times P .
$$

A fixed point of $\varphi$,

$$
\left(x^{*}, z^{*}, m^{*}, y^{*}, p^{*}\right) \in \varphi\left(x^{*}, z^{*}, m^{*}, y^{*}, p^{*}\right),
$$

is shown to be a social equilibrium.

To apply Kakutani's fixed-point theorem, we need compactness of choice sets. Let $\bar{x}=\bar{H} \times \bar{I}$ be the upper bound for numeraire consumption for each consumer. This is the amount over the maximum amount that can be collected from all residents of a development (when $H=\bar{H}$ ). If a consumer consumes $\bar{x}$, someone has to consume a negative amount of the numeraire, which is infeasible. Let each consumer's consumption set be $X \equiv[0, \bar{x}]$. Housing characteristics can be compactified as well: let $Z \equiv\left\{z \in \mathbb{R}_{+} \mid z \leq \bar{z}\right\}$ (see Assumption 3). Clearly, all Pareto-efficient allocations in each $d$ belong to $X^{H[d]} \times Z^{H[d]}$. By taking intersection $\Pi_{d \in \mathcal{D}}\left(\mathcal{F}[d] \cap X^{H[d]} \times Z^{H[d]}\right)$, the domain (and the range) of the fixed-point mapping is nonempty, compact, and convex. The standard argument shows that mappings $\beta, \tilde{\delta}, \rho, \mu, \eta$, and $\sigma$ are nonempty- and convex-valued, and have closed graphs. Thus, there is a fixed point $\left(x^{*}, z^{*}, m^{*}, r^{*}, y^{*}, p^{*}\right)$.

First note that in the fixed point, $y^{*}=0$ holds, since if a unit of a development type is in excess demand, then the price of the unit becomes very high, and consumers who occupy the units would get the lowest possible utility (essentiality of numeraire: consumers might as well choose their outside option $\emptyset$ keeping $I^{\theta}$ since $u^{\theta}\left(I^{\theta}, \emptyset\right)>u^{\theta}(0, z, e, H, h)$ for all $z, e, H$ and $\left.h\right)$. Thus, the housing market must clear in the fixed point.

Now, we show that in each development $d \in \mathcal{D},\left(x^{*}(d), z^{*}(d)\right)$ is an intradevelopment Pareto-efficient allocation (Condition 3$)$. We know that all 
elements of $\left(\tilde{x}(d), z^{*}(d)\right) \in \delta[d]\left(\tilde{x}(d), z^{*}(d)\right)$ are Pareto efficient by the ShaferSonnenschein mapping. However, $x^{*}(d)$ is determined separately as the leftover income in the fixed-point mapping: $x_{h}^{*}(d)=I^{\alpha[d](h)}-p_{h}^{*}(d)$. Thus, at first glance, it may not be clear whether the fixed-point intradevelopment allocation is Pareto efficient or not. We can show that it is indeed Pareto efficient in the following lemma. Note that $x_{h}^{*}(d)>0$ for all $d$ and $h$ by the essentiality of numeraire again.

Lemma A1. At the fixed point of the mapping $\varphi$, for all $d \in \mathcal{D},\left(x^{*}(d), z^{*}(d)\right)$ is an intradevelopment Pareto efficient consumption vector, given that the assignment function of $d, \alpha[d]$ is consistent with actual types of consumers who occupy the units $1, \ldots, H[d]$.

Proof of Lemma A1. Suppose that $\left(x^{*}(d), z^{*}(d)\right)$ is not intradevelopment Pareto efficient. Then, $\mathcal{P}[d]\left(x^{*}(d), z^{*}(d)\right) \neq \emptyset$ holds. By the construction of the Shafer-Sonnenschein mapping $\delta$, for all $(\tilde{x}(d), z(d)) \in \delta[d]\left(x^{*}(d), z^{*}(d)\right)$, $(\tilde{x}(d), z(d)) \neq\left(x^{*}(d), z^{*}(d)\right)$ must hold. However, since $z^{*}(d) \in \operatorname{proj}_{z} \delta[d]\left(x^{*}(d), z^{*}(d)\right)$, $z(d)=z^{*}(d)$ holds. Thus, $x^{*}(d) \neq \tilde{x}(d)$ holds in the fixed point, and we have

$$
u^{\alpha[d](h)}\left(\tilde{x}_{h}(d), z^{*}, e[d], H[d], h\right)>u^{\alpha[d](h)}\left(x_{h}^{*}(d), z^{*}, e[d], H[d], h\right)
$$

for all $1 \leq h \leq H[d]$. However, by mapping $\delta[d]$ (by feasibility $\mathcal{F}[d]$ ),

$$
\sum_{h=1}^{H[d]} \tilde{x}^{\alpha[d](h)} \leq \sum_{h=1}^{H[d]} I^{\alpha[d](h)}-C[e[d], H[d]]\left(z^{*}\right) .
$$

But as we will see below, mapping $\eta$ ensures that in the fixed point, developers get zero profit. That is,

$$
\sum_{h=1}^{H[d]} p_{h}^{*}(d)=C[e[d], H[d]]\left(z^{*}(d)\right) .
$$

Since $\beta$ mapping shows that $x^{\alpha[d](h) *}=\max \left\{0, I^{\alpha[d](h)}-p_{h}^{*}(d)\right\}=I^{\alpha[d](h)}-$ $p_{h}^{*}(d)>0$, we have

$$
\sum_{h=1}^{H[d]} \tilde{x}^{\alpha[d](h)} \leq \sum_{h=1}^{H[d]} x^{\alpha[d](h) *} .
$$

However, again by mapping $\beta$, each type needs a higher income than the fixed point income, $\tilde{x}^{\alpha[d](h)}>x^{\alpha[d](h) *}$. This is a contradiction. Hence, $\left(x^{*}(d), z^{*}(d)\right)$ is intradevelopment Pareto efficient. 
It is important to notice that allocation $\left(x^{*}(d), z^{*}(d)\right)$ is intradevelopment Pareto efficient only when the types who occupy the units in $d$ are actually the ones assigned by $\alpha[d]$. If we look at the fixed-point mapping, it is not obvious whether this is the case (it is possible that a type $\theta \neq \alpha[d](h)$ consumer happily chose unit $h$ in development $d$, and the market for club membership cleared). However, we can show that this is not a problem. Before stating the result, we observe the following. In the fixed point of $\varphi$, suppose that there is $d \in \mathcal{D}$ with $\mu(d)>0$ and $\rho^{\theta}(d, h)>0$ for $\theta \neq \alpha[d](h)$. Then, there exists a positive measure of developments with population assignment $\alpha^{\prime} \neq \alpha[d]$ in the fixed point in the supposed type $d$ development. It turns out that the fixed-point allocation for $d$ is Pareto indifferent to the fixed-point allocation for $d^{\prime}$ for consumer types $\alpha^{\prime}$.

Lemma A2. Suppose in the fixed point that there is a positive measure of supposed type $d$ club with population assignment $\alpha^{\prime}=\alpha\left[d^{\prime}\right] \neq \alpha[d]$. Then, for all $h \in\left\{1, \ldots, H\left[d^{\prime}\right]\right\}, U^{\alpha\left[d^{\prime}\right](h)}\left(x^{*}\left(d^{\prime}\right), z^{*}\left(d^{\prime}\right), h\right)=U^{\alpha\left[d^{\prime}\right](h)}\left(x^{*}(d), z^{*}(d), h\right)$, and the (intradevelopment) allocation $(x(d), z(d))$ is Pareto efficient for members of type $d^{\prime}=\left(e[d], \alpha^{\prime}, H[d]\right)=\left(e\left[d^{\prime}\right], \alpha^{\prime}, H\left[d^{\prime}\right]\right)$ development $\alpha\left[d^{\prime}\right]$.

Proof of Lemma A2. Suppose that $U^{\alpha\left[d^{\prime}\right](h)}\left(x^{*}\left(d^{\prime}\right), z^{*}\left(d^{\prime}\right), h\right)=U^{\alpha\left[d^{\prime}\right](h)}\left(x^{*}(d), z^{*}(d), h\right)$ does not hold for some $h \leq H[d]$. Since a positive measure of $\alpha\left[d^{\prime}\right]$ s choose $\left(x^{*}(d), z^{*}(d)\right), U^{\alpha\left[d^{\prime}\right](h)}\left(x^{*}(d), z^{*}(d), h\right) \geq U^{\alpha\left[d^{\prime}\right](h)}\left(x^{*}\left(d^{\prime}\right), z^{*}\left(d^{\prime}\right), h\right)$ for all $h=$ $1, \ldots, H[d]$. However, since $\left(x^{*}\left(d^{\prime}\right), z^{*}\left(d^{\prime}\right)\right)$ is (intradevelopment) Pareto efficient for $\alpha\left[d^{\prime}\right]$, allocation $(x(d), z(d))$ must be Pareto efficient for members of type $d^{\prime}=\left(e[d], \alpha^{\prime}, H[d]\right)=\left(e\left[d^{\prime}\right], \alpha^{\prime}, H\left[d^{\prime}\right]\right)$ development $\alpha\left[d^{\prime}\right]$.

The rest of the proof is straightforward. Mapping $\rho$ ensures that all types of consumers choose the most-preferred houses (including houses catering to other types of consumers) at the most preferred developments. Mapping $\mu$ shows that only profit-maximizing development-types are provided in the fixed point (and zero profit is ensured by the free entry condition). Finally, with the Walras law, mappings $\eta$ and $\sigma$ guarantee that there is no excess demand in numeraire and housing developments, $z^{*} \leq 0$, in the fixed point by the Gale-Nikaido Lemma (see Debreu 1959, 5.6). Hence, we conclude that the fixed point of $\varphi$ achieves a social equilibrium. This completes the proof of Proposition A1.

Now, let us go back to the entrepreneurial equilibrium. The main difference between the two equilibrium concepts is that in the entrepreneurial 
equilibrium, if a development-type does not exist, then there is no price and intradevelopment allocation for the club type.

Proposition A2. Every social equilibrium is supportable by an entrepreneurial equilibrium.

Proof. Given a social equilibrium $\left(p^{*}(d), z^{*}(d), m^{*}(d)\right)_{d \in \mathcal{D}}$, we construct an entrepreneurial equilibrium $\left(\Gamma^{*}, \mu^{*},(p[\gamma], z[\gamma], e[\gamma], H[\gamma], \alpha[\gamma])_{\gamma \in \Gamma)}\right)$ from it. Let $\mathcal{D}^{*}=\left\{\gamma(d) \in \Gamma: m^{*}(d)>0\right\}$. For all $d \in \mathcal{D}^{*}$, let $\gamma[d]=\left(p^{*}(d), z^{*}(d), e[d], H[d], \alpha[d]\right)$ and $\mu^{*}(\gamma[d])=m^{*}(d)>0$. Clearly, $\Gamma^{*}$ is a finite set. Since $\left(p^{*}(d), z^{*}(d), m^{*}(d)\right)_{d \in \mathcal{D}}$ is a social equilibrium, no consumer has an incentive to switch from the assigned allocation among $\Gamma^{*}$. Thus, the only condition we need to check is Condition 4 of the entrepreneurial equilibrium.

Suppose that Condition 4 of the entrepreneurial equilibrium is violated. Then, there is a nonexisting development $d^{\prime} \in \mathcal{D} \backslash \mathcal{D}^{*}$ that achieves a positive profit and is feasible in the sense that all the types of consumers it invites are willing to join. We can represent any policy $\gamma^{\prime}$ by development type $d^{\prime}$ with $\left(e\left[d^{\prime}\right], \alpha\left[d^{\prime}\right], H\left[d^{\prime}\right]\right)$ and $\left(x\left(d^{\prime}\right), z\left(d^{\prime}\right)\right) \in \mathcal{F}\left[d^{\prime}\right]$ such that for all $h \in\left\{1, \ldots, H\left[d^{\prime}\right]\right\}$,

$$
u^{\alpha\left[\gamma^{\prime}\right](h)}\left(x_{h}^{\alpha\left[\gamma^{\prime}\right](h)}\left(d^{\prime}\right), z_{h}^{\alpha\left[\gamma^{\prime}\right](h)}\left(d^{\prime}\right), e\left[d^{\prime}\right], H\left[d^{\prime}\right]\right) \geq U^{\alpha\left[\gamma^{\prime}\right](h) *},
$$

with at least one strict inequality. Suppose that the resident in the $h$ th unit is strictly better off. Then, by increasing $p_{h}\left(d^{\prime}\right)=I^{\alpha\left[\gamma^{\prime}\right](h)}-x_{h}^{\alpha\left[\gamma^{\prime}\right](h)}\left(d^{\prime}\right)$ slightly, there is an intradevelopment allocation with a budget balance that is superior to the social equilibrium allocation. However, since intradevelopment Pareto efficiency is achieved in development $d^{\prime}$ in the social equilibrium, there is at least one type who strictly prefers the allocation in development $d^{\prime}$ to the assigned allocation in social equilibrium. But all types are free to choose their policies in social equilibrium; so this cannot happen. This is a contradiction. This completes the proof. $\square$

Propositions A1 and A2 prove the existence of entrepreneurial equilibrium.

\section{References}

[1] Allouch, N., J.P. Conley, M. Wooders, 2009, Anonymous price taking equilibrium in Tiebout economies with a continuum of agents: Existence and characterization, Journal of Mathematical Economics 45, 492-510. 
[2] Aumann, R.J., 1966, Existence of competitive equilibria in market with a continuum of traders, Econometrica 34, 1-17.

[3] Berglas, E., 1976, On the theory of clubs, American Economic Review $66,116-121$.

[4] Bewley, T.F. 1981, A critique of Tiebout's theory of local public expenditures, Econometrica 49, pp 713-740.

[5] Debreu, G., Theory of Value, Wiley (New York), 1959.

[6] Ellickson, B., B. Grodal, S. Scotchmer, and W.R. Zame, 1999, Clubs and the market, Econometrica 67, 1185-1217.

[7] Gersbach, H., and H. Haller, 2010, Club theory and household formation, Journal of Mathematical Economics 46, 715-724.

[8] Gersbach, H., H. Haller, and H. Konishi, 2012, Household formation and market, WP.

[9] Greenberg, J., 1979, Consistent majority rules over compact sets of alternatives, Econometrica 47, 627-636.

[10] Helsley, R.W., and W.C. Strange, 1997, Limited developers, Canadian Journal of Economics 30, 329-348.

[11] Henderson, J.V., 1974, The sizes and types of cities, American Economic Review 64, 640-656.

[12] Konishi, H., 1996, Voting with ballots and feet: Existence of equilibrium in a local public good economy, Journal of Economic Theory 68, 480509 .

[13] Konishi, H., 2008, Tiebout's tale in spatial economies: Entrepreneurship, self-selection and efficiency, Regional Science and Urban Economics 38, 461-471, (special issue in honor of Masahisa Fujita).

[14] Konishi, H., 2010, Efficient mixed clubs: Nonlinear-pricing equilibria with entrepreneurial managers (JEA Nakahara Lecture, 2009) Japanese Economic Review 61, 35-63. 
[15] Luque, J., Heterogeneous Tiebout communities with private production and anonymous crowding, forthcoming in Regional Science and Urban Economics.

[16] Mas-Colell, A., 1977, Indivisible commodities and general equilibrium theory, Journal of Economic Theory 16, 443-456.

[17] Mas-Colell, A., 1984, On Schmeidler's theorem, Journal of Mathematical Economics 13, 201-206.

[18] Rosen, S., 1974, Hedonic prices and implicit markets: Product differentiation in pure competition, Journal of Political Economy 82, 34-55.

[19] Rothschild, M., and J.E. Stiglitz, 1976, Equilibrium in competitive insurance markets: An essay on the economics of imperfect information, Quarterly Journal of Economics 40, 629-649.

[20] Scotchmer, S., "Local public goods and clubs," in A.J. Auerbach and M. Feldstein eds., Handbook of Public Economics Vol. \#4, Elsevier Science B.V., 1997-2042, 2002.

[21] Scotchmer, S., and M. Wooders, 1987, Competitive equilibrium and the core in club economies with anonymous crowding, Journal of Public Economics 34, 159-173.

[22] Shafer, W., and H. Sonnenschein, 1975, Equilibrium in abstract economies without ordered preferences, Journal of Mathematical Economics 2, 345-348.

[23] Tiebout, C., 1956, A pure theory of local public expenditures, Journal of Political Economy 64, 416-424.

[24] Wooders, M.H., 1989, A Tiebout theorem, Mathematical Social Sciences $18,33-55$.

[25] Wooders, M.H., 1999, Multijurisdictional economies, the Tiebout hypothesis, and sorting, Proceedings of the National Academy of Sciences Vol. 96 (19), 10585-10587

[26] Zame, W.R., 2007, Incentives, contracts, and markets: A general equilibrium theory of firms, Econometrica 75, 1453-1500. 


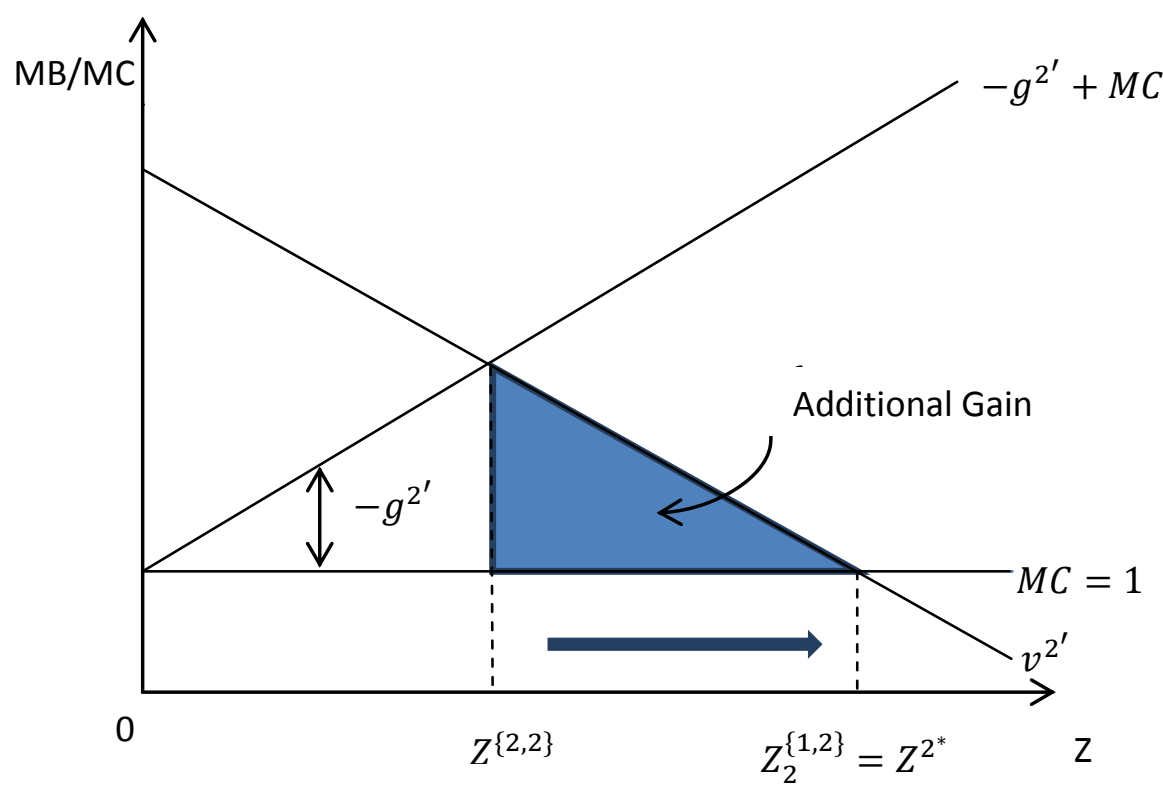

Figure 1

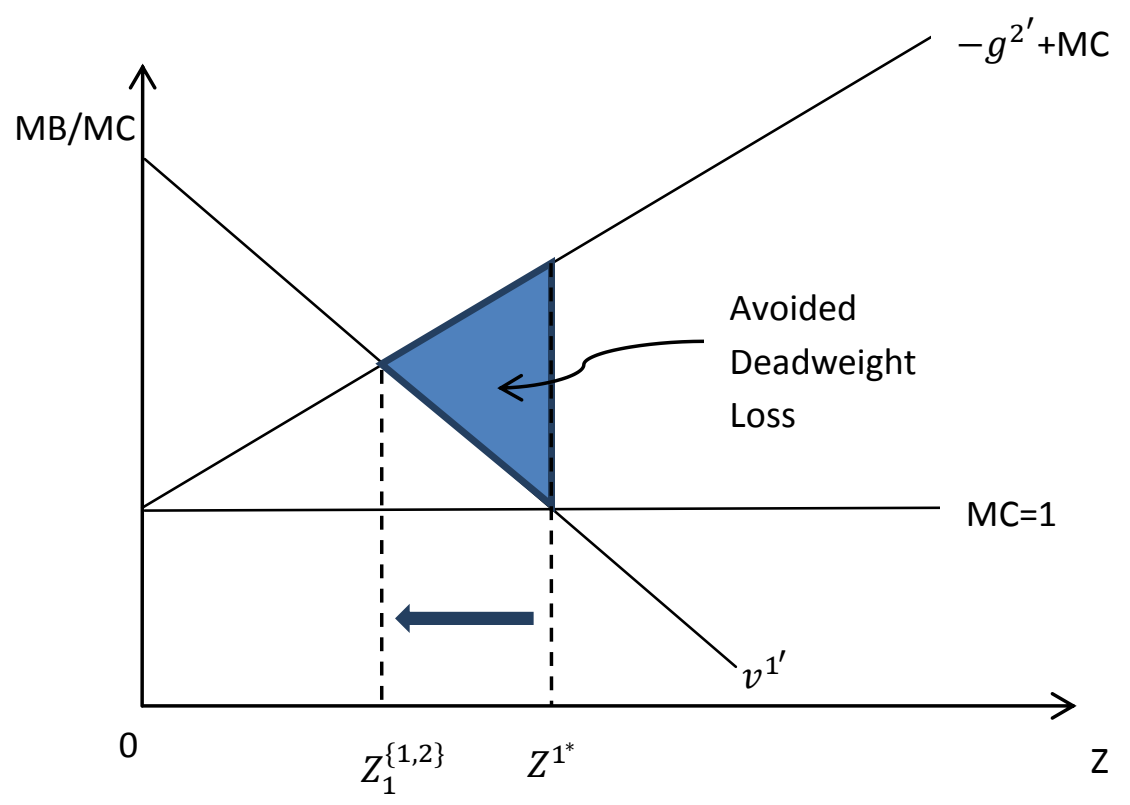

Figure 2 